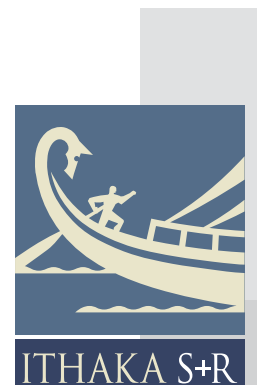

ITHAKA S+R
Ithaka S+R Case Study

\section{Quakers and \\ Slavery}

Haverford College

trilogy.brynmawr.edu/speccoll/quakersandslavery

The Ithaka S+R Case Studies in Sustainability were conducted in partnership with the Association of Research Libraries and were made possible by the generous support of the Institute of Museum and Library Services. A summary report, "Searching for Sustainability: Strategies from Eight Digitized Special Collections," is available at http://www.sr.ithaka. org/research-publications/searching-sustainability. This specific case study was researched and written by Sarah Pickle, Analyst, Ithaka $\mathrm{S}+\mathrm{R}$.

\title{
ABSTRACT
}

Launched in 2009, Quakers and Slavery is a digitized special collection of manumissions, letters, photographs, meeting records, and other rare and unique items from the seventeenth through nineteenth centuries related

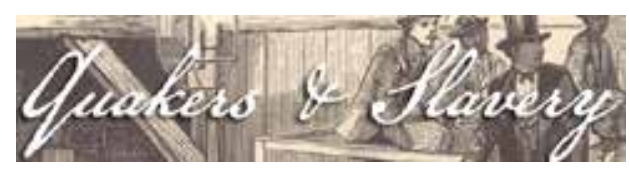
to the antislavery efforts of members of the Religious Society of Friends, or Quakers. Quakers and Slavery is a collaboration between Haverford College and Swarthmore College (both founded by Quakers), and it is one of the most visited sites on Triptych, the platform for digitized special collections shared by the Tri-College partnership of Haverford,

Swarthmore, and Bryn Mawr. The Triptych digital initiative was launched in 2002 as a way to make the creation and ongoing support of digital collections at these colleges more practical. Because the management of the Quakers and Slavery project and additions to the site are covered by funds internal to the Tri-College system, Quakers and Slavery has been able to continue to grow incrementally.

\section{INTRODUCTION}

In 2009, with the support of an Institute of Museum and Library Services (IMLS) grant distributed by the state of Pennsylvania, librarians at Haverford College and Swarthmore College created the Quakers and Slavery online collection by digitizing documents, images, and other items from their holdings that reflect the antislavery sentiment and activism of the Religious Society of Friends, or Quakers, from as early as the seventeenth century. ${ }^{1}$ These Philadelphia-area liberal arts colleges were both founded by the Quakers in the nineteenth century, and their staff were able to create this online collection thanks in large part to the technological infrastructure Haverford and Swarthmore share with Bryn Mawr College as part of the TriCollege (or Tri-Co) partnership.

The partnership was begun informally in the early 1980s and was formalized in 1988 when the presidents of the colleges decided to create a single catalog for the three institutions' libraries. Since then, several other services and activities have also been integrated under the Tri-Co banner, including the libraries' online discovery layer (Tripod) and their collections development, which helps to reduce redundancies among holdings of the three 
libraries. Haverford, Swarthmore, and Bryn Mawr students are allowed to check out books from the libraries of any of the three colleges.

One of the most recent manifestations of the partnership is the schools' digitized collections portal, named Triptych, which serves as the virtual home of the Quakers and Slavery collection. Constituting that collection are books, pamphlets, letters, photographs, minute books of Quaker meetings, selections from sixteen manuscript collections, and more than sixty manumissions-documents granting slaves their freedom. Although little new material has been added to the collection since the completion of the IMLS grant in 2010, the combination of a workflow driven by trained student labor and the existing Triptych partnership has made it easy for Haverford to support modest growth internally at little direct cost.

With a total of 313 items, the Quakers and Slavery collection aims to "highlight the documentary resources of the libraries and to provide, for a range of users, direct access to selected collections through the Internet." As the Society of Friends was the first community in North America to unequivocally condemn slavery, this resource presents a significant corpus of materials related to the history of abolition in the Americas.

\section{BACKGROUND}

The Quaker and Special Collections department at Haverford's library and the Friends Historical Library (FHL) at Swarthmore, which together created Quakers and Slavery, are well established as two of the most prominent repositories of materials exhibiting the history of the Society of Friends in North America. Scholars of American history have long visited Haverford and

Their staff were able to create this online collection thanks in large part to the technological infrastructure Haverford and Swarthmore share with Bryn Mawr College as part of the Tri-College (or Tri-Co) partnership
Swarthmore to work with primary sources housed at the two institutions. Those who wish to examine documents created after 1827 and before 1950 often need to travel to both campuses. In 1827, a schism developed within the Society of Friends between followers of the Quaker preacher Elias Hicks, referred to as the Hicksites, and the rest of the Society, who came to be known as Orthodox. Orthodox Quakers founded Haverford College in 1833, and the Hicksite Quakers founded

Swarthmore in 1969; consequently, materials pertinent to each group were deposited in the library of its respective institution. Included in the holdings of the two libraries are collections are meeting records, family correspondence, account books, journals, photographs, engravings, and miscellaneous manuscripts on topics ranging from women's suffrage to penal reform and temperance. As of 2008, the two colleges had a combined total of 80,000 printed volumes and 6,100 linear feet of manuscript material related to Quaker history. The online Quakers and Slavery collection represents one attempt at the "virtual reunification" of the documentation of Hicksite and Orthodox Quaker life and causes. ${ }^{3}$

Prior to the IMLS grant, the constituent parts of the Quakers and Slavery collection were scattered throughout the two special collections departments. In 2007, when John Anderies, Head of Special Collections at Haverford, and Chris Densmore, his counterpart at Swarthmore's FHL, began to notice that events were being held in the United Kingdom to mark the three hundredth anniversary of the abolition of the slave trade in the British Empire, they wondered why few comparable commemorations were scheduled in the United States for the following year, the three hundredth anniversary of the enactment of the U.S. law prohibiting the importation of slaves. Well aware of the early and prominent role Quakers played in the abolition movement, Anderies and Densmore decided to create an online resource that would both make important materials from 
their colleges' collections accessible to scholars around the world and preserve those materials from too much handling by visitors, a concern given the popularity of the physical collections. Around the same time, the two colleges also began to collaborate with the McNeil Center of Early American Studies at the University of Pennsylvania and other scholars on a conference on the topic of the Quakers and slavery. The event, titled "Quakers and Slavery, 1657-1865: An International Interdisciplinary Conference," was held in November 2010 at the McNeil Center, Haverford, and Swarthmore, and it featured material exhibitions from both Haverford's and Swarthmore's repositories. ${ }^{4}$

The convergence of the conference and the interest of Anderies and Densmore helped to build momentum around the topic of Quakers and slavery. Working from a timeline of key events in the history of Quaker abolition efforts that they had prepared, and with the help of scholars in the field, the two librarians began to create a list of key items for digitization dating from the seventeenth century through the Civil War. They retrieved the documents from their repositories and began to assemble a small advisory board that would later

Quakers and Slavery collection is closely aligned with the history, values, and identities of the institutions in which it was created assist with identifying scholars to write short contextual articles for a topical website to be created after the items in the bibliography were digitized. With a prioritized list of documents in hand and a plan for the website, the project leaders sought and were awarded financial support from IMLS. After

the collection was assembled, digitized, and added to Triptych, students hired to work on the project worked under the direction of Anderies and Densmore to create the Quakers and Slavery virtual exhibit website, which aimed to share both the primary materials and contextualizing commentary. ${ }^{5}$ With help from the advisory board, several scholars, researchers, and project staff were recruited to submit short essays highlighting themes (e.g., white slaves, Quaker women), people (George Fox, Isaac T. Hopper), and organizations (the Philadelphia Free Produce Association of Friends, the Underground Railroad) represented in the online collection.

The original IMLS grant was for $\$ 32,964$ and was awarded through the federal agency's state-administered Library Services and Technology Act (LSTA). All the grant funds were dedicated to student labor for the digitization and creation of records for 4,151 pages and images of journals, photographs, objects (e.g., medals, ceramics), letters, meeting minutes, and more; the development of a topical website with essays and links to the collection; and the dissemination of these digital materials online through Triptych. In total, the student workers whose wages were covered by the grant included: ${ }^{6}$

- Two scanning and metadata interns (library science graduate students, one per college, with benefits), at .5 FTE, totaling $\$ 20,928$

- Two summer student assistants (undergraduates, one per college, with benefits), at .85 FTE, totaling \$9,156

- Two school-year student assistants (undergraduates, one per college, no benefits), at .15 FTE, totaling $\$ 2,880$

Anderies, Densmore, and the other staff who trained and supervised the students all had permanent positions at their institutions and did not need external financial support. Additionally, all overhead was covered by the libraries, and no new equipment needed to be purchased because Haverford and Swarthmore already owned the flat-bed scanners, computers, and software used for digitization and processing. Finally, the CONTENTdm platform and servers used by Triptych were covered by the dues the colleges contribute to their partnership, with the salaries of the staff supporting this infrastructure paid by Bryn Mawr. 


\section{SUSTAINABILITY STRATEGY}

Since 2010, the Friends Historical Library has made no additions to Quakers and Slavery. Quaker and Special Collections includes new items when it receives special requests and when enough student staff hours are available to check off materials from a short list of items the library has rediscovered since the grant ended and wants to digitize; so far, it has uploaded only a handful of items (close to 100 pages) since 2010. Additionally, a local museum at Arlington Cemetery in Drexel Hill, Pennsylvania has approached the Haverford library about participating in further development of materials related to Quakers, slavery, and the Underground Railroad, and Anderies is hopeful that this relationship could serve as a model for slowly increasing the size of the Quakers and Slavery online collection, especially because, as both he and Densmore freely admit, any further large-scale digitization would require new external grant funds to support student labor.

As a resource deeply tied to the communities that founded Haverford and Swarthmore, the Quakers and Slavery collection is closely aligned with the history, values, and identities of the institutions in which it was created. As a result, like other digitized resources drawn from the special collections of the institutions contributing to Triptych, since the end of its IMLS grant it has been able to rely on the support of its home institutions. As long as this network of support is in place, Anderies will be able to continue to gradually add items to Quakers and Slavery.

\section{Economic Model}

The partnership supporting Triptych ensures that no single institution bears too great a burden when it comes to providing ongoing support for its digitized special collections. Triptych's CONTENTdm platform license allows unlimited items, and its costs are evenly divided by Haverford, Swarthmore, and Bryn Mawr. Triptych and the other digital initiatives of the partnership are overseen by partners' Technology Advisory Group, which is made up of staff from each of the three colleges. The salary of Cheryl Klimaszewski, Digital Collections Specialist at Bryn Mawr, is covered by her primary institution; she is the "superuser" for CONTENTdm who can make system-wide changes, and she is seeking to implement workflows and metadata standards. The systems administrator who tends to the servers is paid from the dues each institution contributes as a member

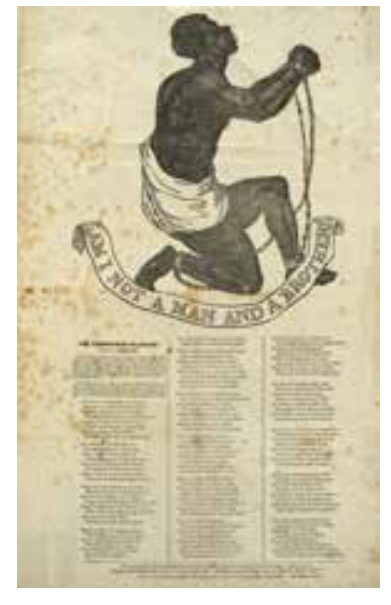

Our countrymen in chains! John Greenleaf Whittier. Courtesy of Swarthmore College. of the partnership. The other relevant budget lines fed by the colleges' dues cover such items as computer supplies, computing software, and software maintenance, all the way down to electricity. Because the annual operating budget of each college's library adds up to less than \$4 million, sharing the costs associated with digitized special collections across Haverford, Swarthmore, and Bryn Mawr is critical to the existence of those resources.

The colleges' investment in providing student labor to the libraries is a second factor contributing to the ongoing support of all of the growing digital collections on Triptych, including Quakers and Slavery. Work-study students are significantly less expensive than librarians to employ, and, thanks to the training and carefully written guides provided by the FHL and Quaker and Special Collections, students were able to scan items, transcribe manuscripts, create and update metadata, and define custom queries for Triptych as well as add essays to the topical website.

On the revenue side of the balance sheet, Densmore and Anderies have been approached by researchers, authors, and television producers who wish to license images from the Quakers and Slavery collection. When this happens, the librarians typically charge $\$ 20$ for one-time use, although the fee can vary depending on the way that the images will be used; decisions are made on a case-by-case basis. Densmore admits, however, that the total amount of money earned thus far is negligible. 
Public Benefit

Audience awareness

Raw visitor numbers for Quakers and Slavery are quite modest. Since the beginning of 2013 (earlier statistics are not available), the collection has become the ninth most popular public collection of the fifty-four on the Triptych platform. Attracting over 15,000 page views between January and mid-June of the year, the site has received 12 percent of Triptych's activity.

These are small numbers, but to Anderies, anecdotal feedback suggests that they reflect the interest of a core group of scholars in the field who may or may not have previously known about the rich Quaker history materials held at Haverford and Swarthmore and who can now begin to explore their collections online rather than on site. Travel is costly and in-person visits always run the risk that another researcher will be working with the materials one wishes to use.

Indeed, the creators of Quakers and Slavery are quick to point to other metrics for measuring success. They underscore that the number of visitors does not reflect the full impact of the collection. The site satisfies Anderies and Densmore's initial intent to commemorate the three hundredth anniversary of the end of the slave trade in North America and to share documents that demonstrate the significant role the Society of Friends played in the abolition movement. Additionally, in the last several years, more of the applications for fellowships offered by both colleges have involved proposals related to the Quakers and slavery than ever before; while in the past, twenty percent of all applications focused on the topic, close to 50 percent do so today. And as Densmore noted, scholarship in the field has blossomed; recent publications have included Michael J. Crawford's The Having of Negroes Is Become a Burden: The Quaker Struggle to Free Slaves in Revolutionary North Carolina (2010), Geoffrey Gilbert Plank's John Woolman's Path to the Peaceable Kingdom: A Quaker in the British Empire (2012), and Brycchan Carey's From Peace to Freedom: Quaker Rhetoric and the Birth of American Antislavery (2012). At the 2010 conference hosted by Haverford, Swarthmore, and the University of Pennsylvania, the online collection was highlighted before the crowd of approximately 125 , and scholars used the website in their presentations.

The audience for the collection is not limited to advanced researchers. Anderies and colleagues have shared the collection with students at their college in bibliographic instruction sessions, and several faculty have used it in classes such as History and Principles of Quakerism, Quaker Social Witness, The Early Republic, and History of North American Borderlands. Students from a local high school have also taken an interest, using it for an assignment on primary source documents.

\section{Student instruction and training}

Quakers and Slavery has also been shared by faculty and librarians at Haverford and Swarthmore with students on their campuses. In fact, students are a major beneficiary of the education derived from building the collection, as well. According to Haverford's Library Director Terry Snyder, her library is a major employer of students, and those who work there have the opportunity to learn skills they might not acquire in the classroom. During the school year, Anderies employs around eight students for six to eight hours per week; during the summer, that number averages about six, although those six work closer to thirty-five hours per week. The students scan, transcribe or perform OCR, and create records of items to be added to CONTENTdm.

It is not only the students who received practical training during the creation of Quakers and Slavery. According to Anderies, although previous digitization projects taught the staff a great deal about the amount of time and training that would be necessary to develop a digitized special collection, Quakers and Slavery was a lesson in how to conceptualize a project from scratch-including applying for a grant and creating a list of items to be digitized—and how to work at a high capacity. 


\section{KEY FACTORS OF SUSTAINABILITY}

1. Triptych: A shared platform, shared responsibilities. Haverford, Swarthmore, and Bryn Mawr each pay dues that support the staff and technical requirements for the back end of the shared Triptych platform for digitized special collections. This arrangement is a relief to already strained budgets at the individual colleges, making it possible for each of the libraries to create these collections, which otherwise they might not be able to afford on their own, and then leave the long-term management of the platform to dedicated staff. Furthermore, it is likely that, by gathering on one platform rare and unique items from all three campuses, more attention is brought to the collections, which could, in turn, demonstrate their value and help secure their future.

For more than a decade, the three colleges have been digitizing items from their special collections in order to preserve them and make them available to users beyond those who can visit their institutions. In 2002, Haverford created the Cope Evans Family Papers collection with the support of an endowment given to the college by the Evans family. Anticipating that he would share lessons from this experience with his colleagues at Swarthmore and Bryn Mawr, Anderies came to see the development of this digital collection as a test run for future work of this nature within the partner system, as it provided the staff with an opportunity to select a delivery platform (CONTENTdm) and to determine the best workflows and practices for creating a digitized collection.

Today, Triptych provides visitors with access to almost 60,000 photographs, letters, maps, lantern slides, broadsides, and various other items that populate the fifty-four collections created by its three member institutions. The back and front ends of the Triptych collections are run centrally at Bryn Mawr, although all support costs are divided evenly, and the management of individual collections_-additions to and deletions from them-takes place at the institutions that created them. The overall goals of the shared platform are 1) to provide a central place for students, faculty, and researchers worldwide to retrieve materials from the colleges' collections and 2) to do so in an efficient and cost-effective way.

2. Developing a system that can be entrusted to nonexperts. Staff at Quaker and Special Collections and at FHL trained student workers to properly handle and scan the objects Anderies and Densmore had selected for the collection. And because the project team sought to make this resource useful to scholars performing text-based work, they also taught and wrote manuals for students so that the latter could perform OCR scans on standard typewritten documents and transcribe materials that were handwritten or that had text illegible to OCR. More advanced students learned to create metadata for the documents, as well. For all these activities, senior staff at the libraries developed workflows and protocols for activities ranging from scanning and processing images to defining custom queries on Triptych and cataloging materials in CONTENTdm in order to help guide students through their work.

By creating clear workflows and protocols and then training students in their use, Haverford and Swarthmore were able to develop Quakers and Slavery inexpensively. Because no experts were needed, the IMLS LSTA grant could be quite modest, only paying for student hours; and when the award was distributed later than expected due to budget delays in the state legislature, the colleges were able to cover the costs. This student-centered strategy also helps to fulfill the mission of these institutions to educate students, teaching them hard skills not acquired in the classroom.

3. Alignment with colleges' mission. As a collection that reflects the history of the communities that founded both Haverford and Swarthmore, Quakers and Slavery has benefitted from the support of its home 
institutions, as demonstrated also by their cosponsoring the Quakers and Slavery conference around the time the site launched. This deep connection also provides the collection with a ready-made audience and will put it in a better position for continued future support from Haverford and Swarthmore.

\section{ONGOING SUSTAINABILITY ISSUES}

- Minimal funding for growth. Despite the low cost of maintaining the collection and the systems in place to ensure that digitization and file processing can be done inexpensively and efficiently, there is little opportunity for Quakers and Slavery to grow. Additional funds would be required for development beyond the current modest rate of additions, and none are available at this time.

- Challenges in coordinating partnership. Because so much of the time invested in this work, i.e., in projects such as Quakers and Slavery, is volunteered by staff, those who first ran Triptych wanted to make contributions as simple as possible by allowing staff on each campus to use whichever metadata standards they adhere to locally. But this leniency led to inconsistencies in keywords and other fields that made it difficult for users to search across the platform due to, for example, spelling differences between collections. In summer 2012, Klimaszewski began to clean up and normalize the metadata in Triptych and to contemplate a strategic plan for further development of the platform, but she would also like to implement clearer workflows so that digital surrogates are sent to her for record standardization before they are uploaded to CONTENTdm.

\section{LESSONS FOR OTHERS}

1. Alignment with the institutional mission can help secure internal support. The Haverford College team that created Quakers and Slavery has been able to continue to support it and incrementally add to it because its institution sees the collection as central to Haverford's mission to serve its students and to collect and share key documents of Quaker history.

2. Smaller institutions may gain from building and leveraging local relationships. A shared commitment to the Triptych platform has thus far ensured the longevity of the collections created by the three participating colleges. Moreover, Haverford's investment in training their students-rather than in hiring an outside firm - to perform digitization, OCR, and transcriptions and to write metadata has made the process of creating and expanding collections inexpensive enough that the library can manage multiple ones at once. 
APPENDIX

Interviewees

John Anderies, Head of Special Collections, Haverford College

Brycchan Carey, Lecturer, University of Kingston, London

Berry Chamness, Information Acquisition and Delivery Coordinator, Bryn Mawr College

Christopher Densmore, Head of Friends Historical Library, Swarthmore College

Cheryl Klimaszewski, Digital Collections Specialist, Bryn Mawr College

Spencer Lamm, Digital Initiatives Librarian, Swarthmore College; TriCollege Library Technology Coordinator

Terry Snyder, Library Director, Haverford College

Resources Consulted

John Anderies and Chris Densmore, Pennsylvania Department of Education, Office of Commonwealth

Libraries, Library Services and Technology Act (LSTA) Digitization Grant Application, 2008.

David Conners, Quakers and Slavery Manual, 2009.

NOTES

1 Haverford College Quaker and Special Collections and Friends Historical Library of Swarthmore

College, "About this Collection," Quakers and Slavery, http://triptych.brynmawr.edu/cdm/landingpage/ collection/HC QuakSlav.

2 John Anderies and Chris Densmore, Pennsylvania Department of Education, Office of Commonwealth Libraries, Library Services and Technology Act (LSTA) Digitization Grant Application (2008), unpublished document.

3 Ibid.

4 A description of the conference and schedule are available at http://www.brycchancarey.com/slavery/ quakersandslavery.htm.

5 Quakers and Slavery, http://trilogy.brynmawr.edu/speccoll/quakersandslavery/.

6 Due to a delayed budget in the Pennsylvania state legislature, IMLS LSTA funds were released several months late. Consequently, Haverford and Swarthmore had to assume some of the early student wages and accelerate their digitization schedule once they received the grant.

This project was made possible in part by the Institute of Museum and Library Services, LG-06-10-0189-10.

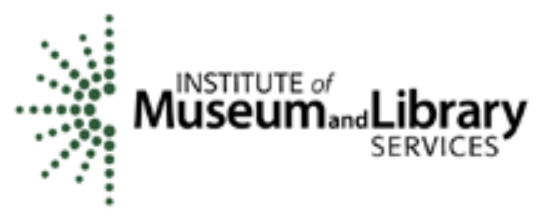

Copyright 2013 Association of Research Libraries. This work is licensed under a Creative Commons Attribution-Non Commercial-ShareAlike 3.0 United States License. To view a copy of the license, please see http://creativecommons.org/licenses/by-nc-sa/3.0/us/. 